\title{
Prevalence and determinants of non-adherence to topical hypotensive treatment in Dutch glaucoma patients
}

\author{
Christine M. G. Olthoff • \\ Juliette G. M. M. Hoevenaars • Bart W. van den Borne • \\ Carroll A. B. Webers • Jan S. A. G. Schouten
}

Received: 30 December 2007 /Revised: 18 August 2008/Accepted: 21 August 2008/Published online: 19 September 2008

(C) The Author(s) 2008. This article is published with open access at Springerlink.com

\begin{abstract}
Background To assess the prevalence and determinants of non-adherence to topical hypotensive treatment in glaucoma patients in order to support interventions targeting enhancement of patient adherence.

Methods One-hundred and sixty-six glaucoma patients, recruited by nationwide multi-stage sampling, filled in an extensive and carefully developed questionnaire covering various theoretically relevant determinants of patient adherence which were categorized as psychosocial aspects, barriers and skills.

Results Prevalence of self-reported non-adherence was $27.3 \%$. Younger patients $(<55$ years of age $)$ had a higher risk of being non-adherent. Forgetfulness, unavailability of eye drops and difficulties with holding the bottle above the eye when applying the eye drops were the most cited reasons for non-adherence. Fifty percent of the patients indicated that they required more information on the correct administration
\end{abstract}

This study was supported by a grant of the national "Health Care Insurance Board", Amstelveen, The Netherlands. The authors do not have any financial relationship with this organization. The authors have full control of all primary data, and allow Graefe's Archive for Clinical and Experimental Ophthalmology to review the data if requested.

\section{M. G. Olthoff}

Department of Ophthalmology, Cologne Hospitals,

Cologne, Germany

J. G. M. M. Hoevenaars • C. A. B. Webers •

J. S. A. G. Schouten $(\bowtie)$

Department of Ophthalmology, Maastricht University Hospital, P.O. Box 5800, 6202 AZ Maastricht, The Netherlands

e-mail: j.schouten@mumc.nl

B. W. van den Borne

Department of Epidemiology, Maastricht University,

Maastricht, The Netherlands of eye drops. There was no association between nonadherence and sex, level of education, type of insurance, duration of disease or family history of glaucoma.

Conclusions Non-adherence to topical glaucoma medication is fairly common. Aids that minimize forgetfulness and delivery systems facilitating the delivery of medications to the eye could be considered to enhance patient adherence before advancing to other therapies with additional risks and costs.

Keywords Glaucoma · Non-adherence · Determinants .

Prevalence

\section{Introduction}

Professionals agree upon the importance of adherence to ocular hypotensive medication in the treatment of glaucoma patients, to reduce the risk of visual impairment [1-5]. A systematic review of 63 studies assessing the relation between adherence and outcomes of medical treatments showed that non-adherent patients have a greater risk of a poor outcome than adherent patients [6]. Because poor adherence can result in ineffectiveness of treatments, improvement of adherence could prevent the need to advance to more aggressive therapies. However, despite the introduction of eye drops with fewer side effects and a simpler medication regimen during the last years, still $10 \%$ to $30 \%$ of glaucoma patients regularly omit prescribed doses [3, 7-11]. Few studies have yet been done that systematically assess the causes of deviation from medication regimen in glaucoma patients in order to improve patient care. Taylor et al. used a qualitative methodology to understand the motivation of 28 glaucoma patients not to comply. Forgetfulness was the most reported reason for 
non-adherence [12]. Tsai et al. developed a systematic classification of a wide range of potential obstacles to adherence to glaucoma medication. Seventy-one barriers to non-adherence were categorized into four groups: social/ environmental factors, patient factors, provider factors and regimen factors [11]. Sleath et al. listed 13 problem areas, and asked patients if they experienced one or more problems with their glaucoma medications. Most reported problems included practical difficulty with drop administration, paying for medications and remembering to take the medication [13]. Interventions for enhancing adherence should be based on reasons for non-adherence, and should be applicable in regular, daily care [14]. Our aim was to quantitatively assess various relevant determinants of adherence to topical glaucoma medication that could later be addressed in an adherence-enhancing intervention.

\section{Materials and methods}

\section{Patients}

We conducted a cross-sectional multi-center study in the Netherlands, in which we enrolled 166 adult patients who were treated for primary open-angle glaucoma. Ethics committee approval was obtained, and all persons gave their informed consent before being included in the study. No selection was made based on duration of the disease or type of glaucoma medication used. Patients were recruited by multi-stage sampling. We took a random sample of 60 ophthalmologists from the directory of the Dutch Ophthalmological Society. They were asked to invite four consecutive glaucoma patients to fill in a self-administered questionnaire during their visit to the outpatient department. In case a patient was not willing or unable to participate in the study, the ophthalmologists were asked to select the next consecutive patient. Selection bias was minimized by asking four consecutive patients as, in this way, ophthalmologists could only select the first patient that they thought to be appropriate for participation. We expected that most ophthalmologists would be able to select a maximum of four patients during one outpatient clinic, and that workload was reduced by the selection of 60 ophthalmologists.

Based on a response rate of $50 \%$ and a target number of 100 patients, we planned to ask 200 patients to participate in the study. The $95 \%$ confidence interval of a frequency of one certain item would be: freq $\pm 1.96 \times($ freq $\times(1-$ freq $) /$ $n)^{1 / 2}$. With 100 responding patients and a frequency of $10 \%$, the $95 \%$ confidence interval would have been $4 \%$ $16 \%$. With 100 responding patients and a frequency of $50 \%$, the $95 \%$ confidence interval would have been $40 \%$ $60 \%$.
Questionnaire

Non-adherence was defined as the failure to take topical hypotensive treatment as prescribed, i.e. the omission of prescribed doses. We aimed to include in the questionnaire all potential causes of non-adherence to glaucoma medication that were reported in the literature and that were put forward by patients and experts. To select appropriate items for the questionnaire, a systematic inventory of the relevant literature was conducted and four focus-group interviews with 21 glaucoma patients from four hospitals were held, one of which was a university hospital. In focus group patients, we made allowance for the duration of glaucoma and membership of the Glaucoma Patient Society. The duration of glaucoma in focus group patients ranged from 1 month to 22 years, and nine patients were members of the Glaucoma Patient Society. Members of the Glaucoma Patient Society were placed in one focus group, as well as patients with a short duration of glaucoma. Reasons for not mixing these patients with other patients included prevention of dominance of some patient groups and the different level of knowledge of members of the Glaucoma Patient Society and patients with short duration of glaucoma compared to other patients. In this way, we obtained a variety in patient characteristics in the focus groups.

Experts in ophthalmology, patient education and pharmacology reviewed the concept version of the questionnaire. In addition, we tested the questionnaire in a pilot study with ten patients. Based on key determinants from health education theory, we distinguished three clusters of causes: psychosocial determinants of behavior (including factors as for example attitude and social influence), barriers (e.g. co-morbidity and understanding) and skills [15]. We listed 34 possible determinants of non-adherence, consisting of 18 psychosocial reasons, six barriers and ten skills. Patients could fill in whether they had never missed an eye drop, whether they had missed an eye drop once or whether they had missed an eyedrop more than once because of the stated reason.

To discover any supplementary topics that could lead to better adherence if addressed in a patient education program, we examined patients' subjective need for information. Therefore, we asked patients to indicate whether they preferred much, some or no information about 22 listed items concerning need for information.

Questions about the various causes of non-adherence were formulated in plain Dutch. Questions covered the past 4 weeks in order to minimize the risk of recall bias.

Statistical analysis

In order to minimize data-entry errors, experienced data typists entered the data twice and checked for discrep- 
ancies. If patients had not answered the question about how often they had missed an eye drop during the past 4 weeks $(n=11)$, we classified them as adherent or non-adherent according to the answers given to the questions concerning causes of non-adherence. Four patients who claimed not to have missed a single dose due to one of the reasons given were classified as adherent. Three patients who had missed an eye drop at least once due to one of the reasons given were classified as non-adherent. Four patients whose status of being adherent or non-adherent could not be determined and eight patients who did not use eye drops for glaucoma treatment at all were excluded from further analysis.

Statistical analyses were performed with 154 patients, using the software package SPSS 10.1. The $\chi^{2}$-test for independence of two nominal variables was employed to examine differences in frequency distributions of categorical variables between adherent and non-adherent patients. A $p$-value of $<0.05$ was used to indicate statistical significance. Univariate logistic models were fitted per item to calculate the odds ratio of being non-adherent.

\section{Results}

Sociodemographic determinants

The response among the ophthalmologists was 73\% (44/ $60)$. Of the 236 questionnaires we had handed out, 166 $(70.3 \%)$ were returned. With respect to the patients, reasons not to participate in the study were cognitive dysfunction, language barriers and lack of time.

Table 1 shows the characteristics of the patients and the prevalence of the omission of doses. Twenty-six percent of the patients reported that they had missed an eye drop once or more than once during the past 4 weeks. After imputation, $27.3 \%$ of the patients were classified as non-adherent.

There was a statistically significant difference $(p=0.01)$ in the proportion of adherent and non-adherent patients between the different age groups (Table 2). The odds ratio of being non-adherent was less in the higher age categories compared to the lowest category ( $<54$ years).
Table 1 Characteristics of the study population and the prevalence of omission of doses during the past four weeks
Data are mean $( \pm \mathrm{SD})$ or number of patients $(\%)$.

${ }^{a}$ Health insurance for patients belonging to higher income categories.

b Health insurance for patients belonging to lower and average income categories.

c Health insurance for civil servants.

${ }^{d}$ Multiple prescriptions possible.

e Others: metipranolol, dipivefrine, aceclidine, apraclonidine, pilocarpine, fixed metipranololpilocarpine combination, fixed timolol-pilocarpine combination, fixed epinephrine-guanethidine, carteolol, dorzolamide, befunolol, others.

f i.e.: not a single dose was omitted.
Characteristics of the study population

\begin{tabular}{|c|c|c|}
\hline $\operatorname{Sex}(n=153)$ & Female & $74(48.4 \%)$ \\
\hline Mean age $(n=153)$ & & $64.5( \pm 12.9)$ \\
\hline \multirow[t]{3}{*}{ Educational level $(n=153)$} & Low & $62(40.5 \%)$ \\
\hline & Moderate & $50(32.7 \%)$ \\
\hline & High & $41(26.8 \%)$ \\
\hline \multirow[t]{3}{*}{ Health insurance $(n=153)$} & Private $^{\mathrm{a}}$ & $56(36.6 \%)$ \\
\hline & Dutch National Health Service ${ }^{b}$ & $91(59.5 \%)$ \\
\hline & Dutch civil servant health insurance ${ }^{c}$ & $6(3.9 \%)$ \\
\hline Duration of glaucoma $(n=145)$ & $\leq 2$ years & $35(24.1 \%)$ \\
\hline \multirow{2}{*}{ Family members with glaucoma $(n=151)$} & Yes & $56(37.1 \%)$ \\
\hline & Do not know & $38(25.2 \%)$ \\
\hline \multirow[t]{4}{*}{ History of surgical or laser therapy $(n=150)$} & None & $97(64.7 \%)$ \\
\hline & Laser therapy & $30(20.0 \%)$ \\
\hline & Surgical treatment & $5(3.3 \%)$ \\
\hline & Both & $18(12.0 \%)$ \\
\hline \multirow[t]{8}{*}{ Prescribed medication $(n=154)^{\mathrm{d}}$} & Latanoprost & $70(45.5 \%)$ \\
\hline & Timolol & $51(33.1 \%)$ \\
\hline & Betaxolol & $22(14.3 \%)$ \\
\hline & Fixed timolol-dorzolamide combination & $9(5.8 \%)$ \\
\hline & Brimonidine & $8(5.2 \%)$ \\
\hline & Levobunolol & $5(3.2 \%)$ \\
\hline & Brinzolamide & $3(1.9 \%)$ \\
\hline & Others $^{\mathrm{e}}$ & $38(24.8 \%)$ \\
\hline \multicolumn{3}{|c|}{ Number of times a dose was missed during the past 4 weeks ( $n=147$ patients) } \\
\hline & $0^{\mathrm{f}}$ & $108(73.5 \%)$ \\
\hline & 1 & $14(9.5 \%)$ \\
\hline & 2 & $11(7.5 \%)$ \\
\hline & 3 & $5(3.4 \%)$ \\
\hline & 4 & $2(1.4 \%)$ \\
\hline & 5 & - \\
\hline & 6 & - \\
\hline & $\geq 7$ & $7(4.8 \%)$ \\
\hline
\end{tabular}


Table 2 Non-adherence by patient characteristics
${ }^{\text {a }} \mathrm{CI}=$ confidence interval

b $\mathrm{NHI}=$ National Health Insurance

c i.e. $\geq 2$ different bottles

\begin{tabular}{|c|c|c|c|}
\hline Patient characteristic & $\begin{array}{l}\% \text { non-adherent } \\
\text { patients }\end{array}$ & $\begin{array}{l}P \text {-value of the } \\
\chi^{2} \text {-test }\end{array}$ & $\begin{array}{l}\text { Unadjusted odds ratic } \\
\left(95 \% \mathrm{CI}^{\mathrm{a}}\right)\end{array}$ \\
\hline Age & & 0.01 & \\
\hline$<55$ y $(n=38)$ & 44.7 & & 1 \\
\hline $55-64$ y $(n=28)$ & 35.7 & & $0.7(0.3-1.9)$ \\
\hline $65-74$ y $(n=50)$ & 16.0 & & $0.2(0.1-0.6)$ \\
\hline$>74$ y $(n=37)$ & 18.9 & & $0.3(0.1-0.8)$ \\
\hline Sex & & 0.63 & \\
\hline Male $(n=79)$ & 29.1 & & 1 \\
\hline Female $(n=74)$ & 25.7 & & $0.8(0.4-1.7)$ \\
\hline Educational level & & 0.70 & \\
\hline Low $(n=62)$ & 24.2 & & 1 \\
\hline Moderate $(n=50)$ & 28.0 & & $1.2(0.5-2.8)$ \\
\hline High $(n=41)$ & 31.7 & & $1.5(0.6-3.5)$ \\
\hline Insurance & & 0.61 & \\
\hline Private/Civil servant $(n=62)$ & 29.0 & & 1 \\
\hline $\mathrm{NHI}^{\mathrm{b}}(n=91)$ & 25.3 & & $0.8(0.4-1.7)$ \\
\hline Duration of disease & & 0.72 & \\
\hline$<1$ year $(n=15)$ & 26.7 & & 1 \\
\hline $1-2$ years $(n=20)$ & 35.0 & & $1.5(0.3-6.4)$ \\
\hline$>2-5$ years $(n=41)$ & 22.0 & & $0.8(0.2-3.0)$ \\
\hline$>5-10$ years $(n=37)$ & 35.1 & & $1.5(0.4-5.6)$ \\
\hline$>10$ years $(n=32)$ & 28.1 & & $1.1(0.3-4.3)$ \\
\hline Family members with glaucoma & & 0.96 & \\
\hline Yes $(n=56)$ & 28.6 & & 1 \\
\hline No $(n=57)$ & 26.3 & & $0.9(0.4-2.0)$ \\
\hline Don't know $(n=38)$ & 26.3 & & $0.9(0.4-2.3)$ \\
\hline Medication & & 0.06 & \\
\hline Beta blocker $(n=48)$ & 22.9 & & 1 \\
\hline Xalatan $(n=47)$ & 21.3 & & $0.9(0.3-2.4)$ \\
\hline Combination $^{\mathrm{c}}(n=24)$ & 50.0 & & $3.4(1.2-9.6)$ \\
\hline Other $(n=35)$ & 25.7 & & $1.2(0.4-3.2)$ \\
\hline Surgery/laser treatment & & 0.08 & \\
\hline None $(n=97)$ & 25.8 & & 1 \\
\hline Laser only $(n=30)$ & 43.3 & & $2.2(0.9-5.2)$ \\
\hline Surgery only/surgery + laser $(n=23)$ & 17.4 & & $0.6(0.2-2.0)$ \\
\hline
\end{tabular}

With respect to type of medication, differences in proportion of adherent and non-adherent patients did not reach statistical significance $(p=0.06)$. The unadjusted odds ratio for non-adherence in the patient group who received a combination therapy ( $\geq 2$ different bottles) was 3.3 (95\% CI $[1.2 ; 9.6], p=0.02)$ with patients prescribed a beta-blocker serving as reference group. There was no difference between patients prescribed a beta-blocker and patients prescribed latanoprost.

Patients who had undergone laser treatment seemed to be at greater risk for non-adherence than patients who had no history of surgical or laser treatment. However, this association was not statistically significant.

There were no statistically significant differences in proportion of adherent and non-adherent patients for sex, level of education, type of insurance, duration of disease or family history of glaucoma.
Psychosocial determinants, barriers and skills

The proportion of patients who admitted to having forgotten to administer their eye drops once or more was $26.7 \%(39 / 146)$. Other psychosocial reasons were reported by $0.7 \%$ to $4.2 \%$ of the patients (Table 3 ).

Twenty-three patients out of 145 (15.9\%) reported that they had omitted their medication once or more than once because they did not have eye drops or gel with them (Table 4). All other barriers were reported as a reason for omission of eye drops by less than $5 \%$ of the patients.

Generally, difficulties with the correct administration of eye drops were reported by a greater proportion of patients as a reason for omission of doses than were psychosocial causes or barriers (Table 4). Difficulties with holding the bottle properly above their eye were most often reported (16\% of the patients). 
Table 3 Psychosocial determinants of non-adherence in glaucoma patients

\begin{tabular}{|c|c|c|c|c|c|c|}
\hline \multirow[t]{2}{*}{ Reason } & \multicolumn{2}{|c|}{$\begin{array}{l}\text { Never } \\
\text { missed }\end{array}$} & \multicolumn{2}{|c|}{$\begin{array}{l}\text { Missed } \\
\text { once }\end{array}$} & \multicolumn{2}{|c|}{$\begin{array}{l}\text { Missed more } \\
\text { than once }\end{array}$} \\
\hline & $n$ & $\%$ & $n$ & $\%$ & $n$ & $\%$ \\
\hline \multicolumn{7}{|l|}{ Psychosocial determinants } \\
\hline I forgot to take the eye drops $(n=146)$ & 107 & 73.3 & 23 & 15.7 & 16 & 11.0 \\
\hline I found putting eye drops in my eye to be such a nuisance $(n=143)$ & 137 & 95.8 & 2 & 1.4 & 4 & 2.8 \\
\hline I suffered from side-effects $(n=144)$ & 139 & 96.5 & 2 & 1.4 & 3 & 2.1 \\
\hline I did not consider my glaucoma serious enough $(n=143)$ & 138 & 96.5 & 4 & 2.8 & 1 & 0.7 \\
\hline I did not use the eye drops at certain points in time $(n=147)$ & 142 & 96.6 & 2 & 1.4 & 3 & 2.0 \\
\hline I thought they would do more harm than good $(n=144)$ & 140 & 97.2 & 1 & 0.7 & 3 & 2.1 \\
\hline I found using eye drops uncomfortable $(n=143)$ & 139 & 97.2 & 2 & 1.4 & 2 & 1.4 \\
\hline I thought that it would not help anyway $(n=144)$ & 141 & 97.9 & 1 & 0.7 & 2 & 1.4 \\
\hline I already had to take the eye drops so often $(n=143)$ & 140 & 97.9 & 2 & 1.4 & 1 & 0.7 \\
\hline I thought I would be able to do without eye drops or gel $(n=142)$ & 140 & 98.6 & 0 & 0.0 & 2 & 1.4 \\
\hline I used the eye drops when it suited me $(n=143)$ & 141 & 98.6 & 1 & 0.7 & 1 & 0.7 \\
\hline My glaucoma did not deteriorate $(n=143)$ & 141 & 98.6 & 0 & 0.0 & 2 & 1.3 \\
\hline I can still see well $(n=143)$ & 141 & 98.6 & 0 & 0.0 & 2 & 1.4 \\
\hline I did not consider it important to use the eye drops $(n=143)$ & 141 & 98.6 & 0 & 0.0 & 2 & 1.4 \\
\hline I thought that I did not have to use the eye drops because my eyes were giving me trouble $(n=143)$ & 141 & 98.6 & 0 & 0.0 & 2 & 1.4 \\
\hline I thought that I would not become blind anyway $(n=141)$ & 140 & 99.3 & 0 & 0.0 & 1 & 0.7 \\
\hline Because others did not consider it important $(n=143)$ & 142 & 99.3 & 0 & 0.0 & 1 & 0.7 \\
\hline Because my partner thought it to be unnecessary $(n=143)$ & 143 & 100.0 & & & & \\
\hline
\end{tabular}

Table 4 Barriers and skills as reasons for non-adherence in glaucoma patients

\begin{tabular}{|c|c|c|c|c|c|c|}
\hline \multirow[t]{2}{*}{ Reason } & \multicolumn{2}{|c|}{$\begin{array}{l}\text { Never } \\
\text { missed }\end{array}$} & \multicolumn{2}{|c|}{$\begin{array}{l}\text { Missed } \\
\text { once }\end{array}$} & \multicolumn{2}{|c|}{$\begin{array}{l}\text { Missed more } \\
\text { than once }\end{array}$} \\
\hline & $n$ & $\%$ & $n$ & $\%$ & $n$ & $\%$ \\
\hline \multicolumn{7}{|l|}{ Barriers } \\
\hline I did not have eye drops, gel or salve with me $(n=145)$ & 122 & 84.1 & 17 & 11.7 & 6 & 4.2 \\
\hline The eye drops, gel or salve had run out $(n=147)$ & 141 & 95.9 & 6 & 4.1 & 0 & 0.0 \\
\hline I suffered from another illness that prevented me from administering the eye drops properly $(n=145)$ & 142 & 97.9 & 3 & 2.1 & 0 & 0.0 \\
\hline I did not have anyone to assist me with administering the eye drops $(n=145)$ & 144 & 99.3 & 1 & 0.6 & 0 & 0.0 \\
\hline I did not know how often or at what time I had to use the eye drops $(n=145)$ & 144 & 99.3 & 1 & 0.7 & 0 & 0.0 \\
\hline I did not quite understand the prescription $(n=144)$ & 144 & 100.0 & & & & \\
\hline \multicolumn{7}{|l|}{ Skills } \\
\hline I was not able to hold the bottle properly above my eye $(n=149)$ & 125 & 83.9 & 12 & 8.1 & 12 & 8.1 \\
\hline I did not feel whether the drop landed in my eye $(n=144)$ & 128 & 88.9 & 8 & 5.6 & 8 & 5.6 \\
\hline I touched my eye with the bottle $(n=145)$ & 129 & 89.0 & 13 & 9.0 & 3 & 2.1 \\
\hline I could not see the bottle above my eye well $(n=147)$ & 132 & 89.8 & 8 & 5.4 & 7 & 4.8 \\
\hline I was not able to squeeze the bottle well $(n=147)$ & 137 & 93.2 & 5 & 3.4 & 5 & 3.4 \\
\hline I was not able to pull my eyelid down sufficiently $(n=147)$ & 139 & 94.6 & 4 & 2.7 & 4 & 2.7 \\
\hline I did not know well how to administer the eye drops properly $(n=145)$ & 143 & 98.6 & 2 & 1.4 & 0 & 0.0 \\
\hline I found it difficult to remove the cap from the bottle $(n=145)$ & 144 & 99.3 & 1 & 0.7 & 0 & 0.0 \\
\hline I could not hold the bottle well $(n=146)$ & 145 & 99.3 & 1 & 0.7 & 0 & 0.0 \\
\hline It was difficult to open the sealed bottles $(n=145)$ & 145 & 100.0 & & & & \\
\hline
\end{tabular}


Finally, $50 \%$ of the patients indicated that they would like to receive more information on how to administer eye drops correctly (data not shown).

\section{Discussion}

Non-adherence to topical hypotensive treatment continues to be a considerable obstacle in the treatment of glaucoma patients, despite the recent development of drugs with relatively simpler treatments and fewer side-effects. In order to make a thorough inventory of the theoretically relevant determinants of non-adherence and their frequency distribution in glaucoma patients, we systematically developed an extensive questionnaire, including questions on psychosocial aspects, potential barriers and skills.

The systematically developed questionnaire, based on focus group interviews, opinions of experts and a pilot test, included various causes of non-adherence. As the questions were formulated in plain Dutch and $95 \%$ of non-adherent patients reported one or more causes of non-adherence, socially acceptable responses are not expected. The risk of recall bias was minimized by asking about the previous 4 weeks. Moreover, $29.7 \%$ of the questionnaires were not returned for analysis, and it is not known whether patients who refused to be included were adherent or non-adherent. Possible bias in the interpretation of the data from this ignorance cannot be excluded. Reasons suggested by patients for not participating were cognitive dysfunction, language barriers and lack of time. Incentives were included for both the ophthalmologists and the patients to improve participation, and all ophthalmologists were contacted by telephone after 2 to 3 weeks and by mail after 6 to 8 weeks. With regard to the selection of patients, it is difficult to assess case order. As described earlier, selection bias was minimized by asking ophthalmologists to invite four consecutive patients to participate. It was the best method for reducing selection bias when compared to the situation in which each ophthalmologist selects one patient, or when compared to alternative methods that select patients in non-randomly selected hospitals, during pharmacy visits or from members of the Glaucoma Patient Society.

In this study, adherence was defined quite strictly as missing an eye drop once or more. Different studies use varying definitions of adherence and different assessment methods. Several studies define adherence as strictly as we did [11, 16-21]. Our result of $27.3 \%$ non-adherent patients corresponds with those of other reports that used questionnaires [22, 23], pharmacy refill records [8, 24] or electronic medication monitors [25] to assess adherence. Based on a systematic review of 569 studies from 1948 to 1998, involving 17 disease conditions, an average non-adherence rate of $24.8 \%$ and a non-adherence rate of $27.4 \%$ was found for eye disorders [26]. Although self-reported adherence is a subjective measure of adherence, it has been shown to be a much better measure of adherence than one believed formerly. Adherence data assessed by electronic monitoring and a medication diary were comparable in cancer patients with pain [27]. In a comparison of various methods for measuring adherence to HIV protease inhibitors, patients' self-reported adherence showed relatively high and significant correlations with results from medication event monitoring systems [28].

Our study shows that forgetfulness, unavailability of medication and insufficient skills for the most part contributed to the omission of doses. Side effects, social influence, inconvenience of therapy or a negative attitude towards the treatment only played a minor role. Furthermore, younger patients and those receiving a combination therapy ( $\geq 2$ different bottles) were significantly more likely to be non-adherent.

Our findings are consistent with that of various studies which report forgetfulness as one of the major causes cited by glaucoma patients for the omission of prescribed doses [3, 12, 17, 21, 29]. An intuitively obvious and often-cited reason why glaucoma patients forget to take their eye drops is that there is no immediate disability from the disease and no direct advantage from the eye drops [5]. Non-acceptance of the disease as well as the necessity of chronic treatment may also be part of the cause. Tsai et al. categorized obstacles to medication adherence. Forty-nine percent of obstacles were categorized as social/environmental, $32 \%$ reflected regimen factors, and $16 \%$ involved individual patient factors. Only $3 \%$ of reported causes of non-adherence were of medical provider origin [11].

Insufficient skills or a lack of manual dexterity in many, especially older glaucoma patients or patients with comorbidities have been recognized by different researchers $[1,3,12,13,23,30,31]$. Winfield et al. showed that about half of patients experienced technical difficulties with eye-drop administration, such as aiming, squeezing and blinking [23]. They reported that $72 \%$ of patients were never asked if they had any problems, and that $69 \%$ would not report any problems to their doctor even if asked [23]. Sleath et al. also showed that $44 \%$ of patients experienced difficulty with drop administration, and $14 \%$ of patients had trouble squeezing the bottle [13]. Our study agrees with these findings, as it shows that many patients are having difficulties in correctly administering eye drops, and that many patients require information on this issue.

Our result (that patients receiving a combination therapy were less adherent) corresponds to findings of Robin et al., who reported a significant increase in refill intervals after the addition of a second drug [32]. Moreover, Sleath et al. found that patients using more glaucoma medications 
experienced problems with the application of their therapy more often than patients taking fewer glaucoma medications [13]. Being treated with various topical medications at the same time might be confusing for some, especially older, patients, and seems an obvious reason for nonadherence. A recently undertaken study has objectively measured adherence by the use of electronic monitoring, and found that poorer adherence was associated with more complex regimens, although once-daily drugs in a complex dosing regimen resulted in good adherence [33]. They found a higher percentage of adherence than in our findings, which could be explained by the fact that patients in the study of Robin et al. were informed that their dosing behavior was being monitored [33]. While some studies suggest that reducing dose frequency will enhance adherence [9, 34-36], it has also been reported that many patients say that it would not make it easier to adhere to the regimen, although it would be more convenient, and patients prefer one drop once a day in terms of lifestyle $[11,37,38]$. Stewart et al. reported that $74 \%$ of physicians believed their patients would prefer once a day dosing, and $92 \%$ of physicians believed it would improve adherence. However, only $20 \%$ of patients believed they would be more adherent if they had a once a day dosing regimen [37]. The same association seems to exist for side-effects. Taylor et al. showed that only a few patients report nonadherence because of side-effects, while a lot of patients complain about them [12]. Jampel et al. show in a willingness-to-pay analysis that patients place differing value on certain eye-drop characteristics. Patients were especially willing to pay more for eye drops that did not produce blurring of vision, drowsiness or inhibition of sexual performance. Patients were least willing to pay more for reduction of dose frequency, and for a combination of two medications in one bottle rather than two bottles [39]. We think that a drug regimen with lower dosing frequency and fewer side-effects probably will not be the only solution for the adherence problem.

In our study, patients younger than 55 years of age were significantly less adherent than older patients. The working situation of this younger group, which does not allow the regular use of eye drops, or inconvenient effects such as blurred vision that hinder people in doing their work, might provide an explanation for this difference [29]. However, this study was not designed to discover why younger patients would be less adherent and no cause-effect relationship can be concluded because of the cross-sectional design of the study. An evidence-based review reported nine studies that had investigated the relation between age and non-adherence, and found that none of them reported significant results [9].

The finding that patients who had undergone laser therapy tended to be at higher risk of being non-adherent has to be interpreted with caution. Since the underlying study was cross-sectional, a cause-effect relationship cannot be concluded. Patients who had undergone laser therapy might be a selected group of non-adherent patients who had undergone laser therapy because topical hypotensive treatment was ineffective.

Several intervention studies have already tested the effect of a memory aid $[18,19,40]$ or an education and tailoring program [41] on the prevalence of omission of doses. These studies lacked different aspects of trial quality, yet they all reported a small, but significant improvement of patient adherence. However, there are no data available on the effects of the different interventions in the long run, or on the feasibility or cost-effectiveness of their implementation in daily clinical routine. Newer dosing aids combine alarm features with a dosing lever, and register adherence data $[42,43]$. Others suggest written instructions as a simple and inexpensive intervention, as written instructions improved the accuracy of self-reporting medication regimen [44]. Medication reviews are also seen as a tool for improving adherence [45]. Systematic reviews have shown that several types of intervention, such as technical, educational, behavioral and combined interventions, are effective in improving medication adherence in chronic medical disorders, but the effect on clinical outcomes was small $[35,36]$. However, DiMatteo et al. and Hugen et al. have shown that non-adherence increases the risk of poor outcome of medical treatments $[6,28]$. In general, the most powerful intervention is believed to consist of a combination of educational, behavioural and affective components [46]. No single intervention appears to be superior [47].

Although the present study has not proved it, we expect that adherence-enhancing interventions should pay special attention to the reduction of patient forgetfulness as well as the improvement of medication administration skills. An intervention focusing on other psychosocial determinants or barriers seems unnecessary. In patients in whom the intraocular pressure continues to be high, or progression of visual field loss occurs despite the prescription of a potent anti-glaucoma drug, patients' skills in administering eye drops should be checked, and the use of a dosing aid or memory aid should be considered before turning to laser or surgical therapy.

Acknowledgements This study was supported by a grant of the national "Health Care Insurance Board", Amstelveen, The Netherlands.

Open Access This article is distributed under the terms of the Creative Commons Attribution Noncommercial License which permits any noncommercial use, distribution, and reproduction in any medium, provided the original author(s) and source are credited. 


\section{References}

1. Busche S, Gramer E (1997) Verbesserung der Augentropfenapplikation und Compliance bei Glaukompatienten; eine klinische Studie. Klin Monatsbl Augenheilkd 211:257-262

2. Forsman E, Kivel T, Vesti E (2007) Lifetime visual disability in open-angle glaucoma and ocular hypertension. J Glaucoma $16: 313-319$

3. Konstas AGP, Maskaleris G, Gratsonidis S, Sardelli C (2000) Compliance and viewpoint of glaucoma patients in Greece. Eye 14:752-756

4. Lee DA, Fechtner RD, Fiscella RG, Singh K, Stewart WC (2000) Emerging perspectives on glaucoma: highlights of a roundtable discussion. Am J Ophthalmol 130:S1-S11

5. Zimmerman TJ, Zalta AH (1983) Facilitating patient compliance in glaucoma therapy. Surv Ophthalmol 28:252-257

6. DiMatteo MR, Giordani PJ, Lepper HS, Croghan TW (2002) Patient adherence and medical treatment outcomes; a metaanalysis. Med Care 40:794-811

7. Deokule S, Sadiq S, Shah S (2004) Chronic open angle glaucoma: patient awareness of the nature of the disease, topical medication, compliance and the prevalence of systemic symptoms. Ophthal Physiol Opt 24:9-15

8. Gurwitz JH, Yeomans SM, Glynn RJ, Lewis BE, Levin R, Avorn J (1998) Patient noncompliance in the managed care setting; the case of medical therapy for glaucoma. Med Care 36:357-369

9. Olthoff CMG, Schouten JSAG, Van de Borne BW, Webers CAB (2005) Noncompliance with ocular hypotensive treatment in patients with glaucoma or ocular hypertension. Ophthalmology 112:953-961

10. Rotchford AP, Murphy KM (1998) Compliance with timolol treatment in glaucoma. Eye 12:234-236

11. Tsai JC, McClure CA, Ramos SE, Schlundt DG, Pichert JW (2003) Compliance barriers in glaucoma: a systematic classification. J Glaucoma 12:393-398

12. Taylor S, Galbraith S, Mills R (2002) Causes of non-compliance with drug regimens in glaucoma patients: a qualitative study. J Ocul Pharmacol Ther 18:401-409

13. Sleath B, Robin AL, Covert D, Byrd JE, Tudor G, Svarstad B (2006) Patient-reported behavior and problems in using glaucoma medications. Ophthalmology 113:431-436

14. Elliot R, Barber N, Horne R (2005) Cost-effectiveness of adherence-enhancing interventions: a quality assessment of the evidence. Ann Pharmacother 39:508-515

15. Meertens RM, Schaalma H, Brug J, De Vries N (2000) Determinanten van gedrag [Determinants of behavior]. In: Brug J, Schaalma H, Kok G, Meertens RM, Van der Molen HT (Eds) Gezondheidsvoorlichting en Gedragsverandering; een Planmatige Aanpak [Health promotion and behavior change: a systematic approach]. Van Gorcum, Assen Netherlands, pp 55-72

16. Amon M, Menapace R, Wedrich A, Radax U (1990) Aspekte der Betreuung von Glaukompatienten und deren Auswirkung auf die Compliance. Spektrum Augenheilkd 4:5-8

17. Bour T, Blanchard F, Segal A (1993) [Therapeutic observance and life of patients with primary open-angle glaucoma. Apropos of 341 cases in the department of Marne]. J Fr Ophtalmol 16:380 391(in French)

18. Chang J, Lee D, Petursson G, Spaeth G, Zimmerman T, Hoskins H, Mills R, Brown R, Kass M, Lue J (1991) The effect of a glaucoma medication reminder cap on patient compliance and intraocular pressure. J Ocul Pharmacol 7:117-124

19. Laster S, Martin J, Fleming J (1996) The effect of a medication alarm device on patient compliance with topical pilocarpine. J Am Optom Assoc 67:654-658
20. MacKean JM, Elkington AR (1983) Compliance with treatment of patients with chronic open-angle glaucoma. $\mathrm{Br} \mathrm{J}$ Ophthalmol 67:46-49

21. Patel SC, Spaeth GL (1995) Compliance in patients prescribed eyedrops for glaucoma. Ophthalmic Surg 26:233-236

22. Bloch S, Rosenthal AR, Friedman DS, Caldarolla P (1977) Patient compliance in glaucoma. Br J Ophthalmol 61:531-534

23. Winfield AJ, Jessiman D, Esakowitz L (1990) A study of the causes of non-compliance by patients prescribed eyedrops. Br J Ophthalmol 74:477-480

24. Gurwitz JH, Glynn RJ, Monane M, Everitt DE, Gilden D, Smith N, Avorn J (1993) Treatment for glaucoma: adherence by the elderly. Am J Public Health 83:711-716

25. Kass MA, Meltzer DW, Gordon M, Cooper D, Goldberg J (1986) Compliance with topical pilocarpine treatment. Am J Ophthalmol 101:515-523

26. DiMatteo MR (2004) Variations in patients' adherence to medical recommendations; a quantitative review of 50 years of research. Med Care 42:200-209

27. Oldenmenger W, Echteld M, Wit de R, Sillevis Smit P, Stronks D, Stoter G, Rijt van der C (2007) Analgesic adherence measurement in cancer patients: comparison between electronic monitoring and diary. J Pain Symptom Manage 34:639-647

28. Hugen P, Langebeek N, Burger D, Zomer B, Leusen van R, Schuurman R, Koopmans P, Hekster Y (2002) Assessment of adherence to HIV protease inhibitors: comparison and combination of various methods, including MEMS (electronic monitoring), patient and nurse report, and therapeutic drug monitoring. J Acquir Immune Defic Syndr 30:324-334

29. Kosoko O, Quigley HA, Vitale S, Enger C, Kerrigan L, Tielsch JM (1998) Risk factors for noncompliance with glaucoma follow-up visits in a residents's eye clinic. Ophthalmology 105:2105-2111

30. Brown M, Brown G, Spaeth G (1984) Improper topical selfadministration of ocular medication among patients with glaucoma. Can J Ophthalmol 19:2-5

31. Dietlein TS (2006) Glaukom im Alter; Barrieren fur Aufklaerung und Compliance. Ophthalmologe 103:755-758

32. Robin AL, Covert D (2005) Does adjunctive glaucoma therapy affect adherence to the initial primary therapy? Ophthalmology 112:863-868

33. Robin A, Novack G, Covert D, Crockett R, Marcic T (2007) Adherence in glaucoma: objective measurements of once-daily and adjunctive medication use. Am J Ophthalmol 144:533-540

34. Mansukani SS (2002) Improving adherence to drug-treatment regimens for glaucoma. Manag Care 11:49-53

35. Kripalani S, Yao X, Haynes B (2007) Interventions to enhance medication adherence in chronic medical conditions; a systematic review. Arch Intern Med 167:540-550

36. Dulmen van S, Sluijs E, Dijk van L, Ridder de D, Heerdink R, Bensing J (2007) Patient adherence to medical treatment: a review of reviews. BMC Health Serv Res 7:55

37. Stewart WC, Konstas AGP, Pfeiffer N (2004) Patient and ophthalmologist attitudes concerning compliance and dosing in glaucoma treatment. J Ocul Pharmacol Ther 20:461-469

38. Buller AJ, Morgan LH, Hercules BL (2007) Patients prefer onedaily glaucoma drops. Graefes Arch Clin Exp Ophthalmol 245:293-294

39. Jampel HD, Schwartz GF, Robin AL, Abrams DA, Johnson E, Miller RB (2003) Patient preferences for eye drop characteristics. Arch Ophthalmol 121:540-546

40. Sclar D, Skaer T, Chin A (1991) Effectiveness of the C Cap in promoting prescription refill compliance among patients with glaucoma. Clin Ther 13:396-400

41. Norell SE (1979) Improving medication compliance: a randomised clinical trial. Br Med J 2:1031-1033 
42. Flowers B, Wand M, Piltz-Seymour J, Berke S, Day D, Teague J, Smoot T, Landry T, Bergamini M, Mallick S (2006) Patients' and physicians' perceptions of the Travoprost dosing aid: an open-label, multicenter study of adherence with prostaglandin analogue therapy for open-angle glaucoma or ocular hypertension. Clin Ther 28:1803-1811

43. Boden C, Sit A, Weinreb RN (2006) Accuracy of an electronic monitoring and reminder device for use with travoprost eye drops. J Glaucoma 15:30-34

44. Kharod BV, Johnson PB, Nesti HA, Rhee DJ (2006) Effect of written instructions on accuracy of self-reporting medication regimen in glaucoma patients. J Glaucoma 15:244-247
45. Lefante JJ, Harmon GN, Roy W, Fontenot S, Brown K, Webber L (2005) The effect of medication reviews in a rural community pharmacy assistance program: the cenla medication access program. J Pharm Pract 18:486-492

46. Roter DL, Hall JA, Merisca R, Nordstrom B, Cretin D, Svarstad B (1998) Effectiveness of interventions to improve patient compliance; a meta-analysis. Med Care 36:11381161

47. Peterson A, Takiya L, Finley R (2003) Meta-analysis of trials of interventions to improve medication adherence. Am J Health Syst Pharm 60:657-665 